9. Leshchynsky, A. (1939). Trudovaya knizhka [The Employment history]. [Manuscript] The archive of the Kharkiv National I. P. Kotlyarevsky University of Arts, Kharkiv. [in Russian].

10. Simonov, P. (1985). O dvuh raznovidnostyah neosoznavaemogo psihicheskogo: pod- i sverhsoznanii [Two Different Types of Unconscious Psychic Phenomena: Sub- and supra-consciousness]. Bessoznatelnoe : Priroda. Funktsii. Metodyi issledovaniya [The Unconscious: Nature. Functions. Methods of Study], 4, pp. 149-159. [in Russian].

11. Sirotin, I. (2017). O tom, chto vspomnilos... [What was remembered...]. Moscow, 84 p. [in Russian].

12. Sirotin, P. (2013). Ob A. A. Leshchynskom [About A. A. Leshchynsky]. Formuvannja Tvorchoji Osobystosti v Informacijnomu Prostori Suchasnoji Kuljtury [Formation of creative personality in the information space of modern culture], pp. 27. [in Russian].

13. Shhelkanovceva, O. (2010). Pam'jati Adolfa Leshchynskogo. Tvorchyj shljakh tryvalistju v zhyttja [In memory of Adolf Leshchynsky. Creative way in life expectancy]. Chasopys [Journal of Tchaikovsky National Music Academy of Ukraine], (2), pp. 187-195. [in Ukrainian].

Стаття надійшла до редакиіï 04.01.2019 p.

УДК 780.643.1:780.616.432]:781.68.071.1

ORCID 0000-0002-7159-7399

\title{
Владимир Метлушко
}

Краснодарский государственный институт культуры

ОСОБЕННОСТИ ИНТЕРПРЕТАЦИИ ИНСТРУМЕНТАЛЬНЫХ ПАРТИЙ В «ЧЕТЫРЁХ ПЬЕСАХ ДЛЯ КЛАРНЕТА И ФОРТЕПИАНО» ОР. 5 А. БЕРГА

Метлушко В. А. Особенности интерпретации инструментальных партий в «Четырёх пьесах для кларнета и фортепиано» ор. 5 А. Берга. Рассмотрены Четыре пьесы для кларнета и фортепиано ор. 5 А. Берга - композитора, творчество которого связано с развитием новой музыки прошлого века. Раскрываются используемые в пьесах новые приёмы и способы звукоизвлечения, темброво-фонические возможности кларнета и фортепиано. Выявляются принципы фразировки и артикуляции, динамический рельеф каждой из пьес, авторские тем- 
пово-метрономические предписания, основополагающие элементы музыкального тематизма и синтаксиса, влияющие на создание интерпретационных версий. Отмечается, что Четьре пьесы для кларнета и фортепиано ор. 5 А. Берга относятся к числу знаковых произведений в репертуаре современных исполнителей камерной музыки. Многообразие эмоционально-образных красок, виртуозность, необходимость проявления исполнительской инициативы в процессе воссоздания композиторского замысла послужили импульсом к более активному использованию кларнета в жанрах ансамблевой музыки

Ключевые слова: кларнет, образность, тематизм, приёмы и способы звукоизвлечения, Четыре пьесы для кларнета и фортепиано ор. 5 А. Берга.

Метлушко В. О. Особливості інтерпретації інструментальних партій у «Чотирьох п'ссах для кларнета і фортепіано» ор. 5 А. Берга. Розглянуто Чотири n'єси для кларнета і фортепіано ор. 5 А. Берга - композитора, творчість якого пов'язана з розвитком нової музики минулого століття. Розкриваються використовувані у п'єсах нові прийоми і способи звуковидобування, темброво-фонічні можливості кларнета і фортепіано. Виявляються принципи фразування i артикуляції, динамічний рельєф кожної з п'єс, авторські темпово-метрономічні вказівки, основоположні елементи музичного тематизму і синтаксису, що впливають на створення інтерпретаційних версій. Відзначається, що Чотири n'єси для кларнета і фортепіано op. 5 А. Берга відносяться до числа знакових творів у репертуарі сучасних виконавців камерної музики. Різноманіття емоційно-образних фарб, віртуозність, необхідність прояву виконавської ініціативи у процесі відтворення композиторського задуму виступили імпульсом до активнішого використання кларнета в жанрах ансамблевої музики.

Ключові слова: кларнет, образність, тематизм, прийоми і способи звуковидобування, Чотири п'єси для кларнета і фортепіано ор. 5 А. Берга.

Metlushko V. O. The peculiarities of the instrumental parts interpretation in "Four Pieces for Clarinet and Piano" op. 5 by A. Berg.

Background. Chamber instrumental music written for a clarinet follows the fate of so-called small genres in the $\mathrm{XX}^{\text {th }}$ century. The researches in a varying degree connected with problems of the music written for a clarinet or with its participation are very various. However, features of use of a clarinet in chamber genres are researched, as a rule, in aspect of wider perspective. Owing to this fact information on many compositions which entered the repertoire of modern performers in scientific and methodical literature either is absent, or does not exhaust all complex of the questions arising in connection with updating of musical language at preservation of the developed receptions of the instrumental and ensemble composing.

Objectives. The purpose of the article is to reveal the features of chamber and instrumental ensemble in Four Pieces for Clarinet and Piano by A. Berg in terms of 
interpretation of technical and expressive opportunities of a clarinet and role functions of parts.

Methods. Structurally functional, compose-dramaturgic and comparative methods of research are used.

Results. As the presented literature testifies, the performer, first of all, should get acquainted with the scientific researches in order to facilitate the subsequent interpretation process. This is important for understanding not only the figuratively emotional and meaningful side of music, but also the novelty of the ensemble ratio of instrumental voices. From this point of view, the clarinetist should be aware of his part both in its individual features, and as an integral part of a single thematic process. It is advisable to recall that the previous musical practice has formed different types of the ratio of parts. Atonality of the Four Pieces op. 5, associated with the avoidance of tonal landmarks and based on the expressiveness of interval clutches, predetermined the emergence of a new quality of ensemble technique, which declares itself in leveling the concept of solo timbre, accompaniment techniques, and open interchange of thematic material. Outwardly, all these signs are present in the musical text, but the writing technique itself directs the musical process towards the creation of a single intoning space in which the participating timbre-register «individualities» appear to be components of a polyphonic texture. Despite this, the idea of ensemble in a broad sense is preserved, which allows us to consider the clarinet part as a relatively independent phenomenon. So, the plays collected in an opus assume possession of a various palette of articulation and dynamic means, capable to transfer thin change of lyrical moods. Their contrast is exhibited already in the first play, which aims the performer to quickly switch to a different emotional mood in the absence of large-scale thematic structures. Against the background of the multievent first play, the two middle ones are distinguished by their consistency of the figurative plan. Hence a more modest palette of strokes, articulation, tempo, dynamic changes. This kind of composer's installation is largely due to the fact that they are enlarging the semantic ideas that were outlined at the beginning of the opus. Due to this, there is a bright contrast, a sharp change of emotional state. Details of this kind raise the requirements for the quality of performance and reveal the truly virtuosic nature of miniatures in the absence of traditional concert techniques. Final op. 5 is similar to the first play by the presence of contrasting elements. Its complexity is indicated both by the rich texture of the piano part, distinguished by a complex rhythmic pattern, and the heterogeneity of the techniques in the clarinet part, where the expressive solo cantilena is adjacent to the background tremolo, angular non-legato motifs, written out by a group of thirty-second in a 9:1 ratio, register spread, sharp dynamic gradations from $p$ to $f f$. The composer here remains true to himself, prescribing all tempo, dynamic, expressive techniques. Recall that the requirement of long pauses between plays, on the one hand, helps to switch to a different emotional state, on the other hand, complicates the act of performance due to the fact that ensemble artists must find that measure of restraint of silence, which, while retaining the impression of the preceding, does not destroy the immediate contact with 
the audience. It is impossible to ignore the fact that in the absence of extraordinary innovations in the field of performing techniques, the composer opens the way for further discoveries in this area.

Conclusions. The results of the research summarizing analytical observations, including those in the literature we know about, and evaluating the creative discoveries of A. Berg in Four Pieces for Clarinet and Piano op. 5 taking into account the subsequent compositional practice, let us highlight a few fundamental, in our opinion, moments. First, op. 5 is distinguished by a radical renewal of the musical language, predicting the expansion of the boundaries of an established tradition; secondly, he became the ancestor of a new type of ensemble; thirdly, it allowed to treat the pause as an important component of the artistic intent, as an image of meaningful silence; fourthly, demonstrated a new understanding of software based on the symbolism of sounds and numbers; fifthly, he revealed a deep connection with the tradition of changing musical patterns. In this context, from the cycle by A. Berg stretched a lot of threads to the works of composers belonging to different generations and national cultures. This allows us to speak about the weighty significance of this opus in the history of the development of clarinet - not only ensemble, but also solo music. We conclude that at the same time, the real compositional practice of the subsequent time reflected the multi-vector nature of creative interests, characteristic of the music of the twentieth century, where, along with the search for renewing principles, the established methods of instrumental.

Keywords: clarinet, figurativeness, thematic, techniques and ways of picking, A. Berg's Four Pieces for Clarinet and Piano op. 5.

Постановка проблемы. Камерно-инструментальная музыка с участием кларнета в XX веке «разделяет судьбу» многих так называемых малых жанров. В условиях кризиса музыкального языка, поиска новых систем звуковысотной организации, отхода от симфонии, несущей на себе бремя устоявшейся традиции, стремительного взлёта исполнительского мастерства, базирующегося на прочной основе профессионального образования, наиболее востребованными оказываются различные формы ансамблевого и сольного музицирования. Исследования, в той или иной степени связанные с изучением музыки, написанной для кларнета и с его участием, достаточно разнообразны. Однако особенности использования кларнета в камерных жанрах, как правило, затрагиваются по касательной, в аспекте более широкой проблематики. В силу этого информация о многих сочинениях, вошедших в репертуар современных исполнителей, в научно-методической литературе либо отсутствует, либо не исчерпывает всего комплекса во- 
Особенности интерпретации инструментальных партий в «Четырёх пьесах...

просов, возникающих в связи с обновлением музыкального языка при сохранении сложившихся приёмов инструментально-ансамблевого письма. Очерченная ситуация подтверждает актуальность предложенной темы.

Анализ последних исследований и публикаций. Четыре nbecbl для кларнета и фортепиано ор. 5 А. Берга достаточно редко попадают в поле зрение музыковедов, несмотря на то, что многие сочинения композитора, различные грани его стиля, прежде всего, связанные с открытиями А. Шёнберга, получили достаточно широкую разработку в отечественной литературе. Отметим масштабный труд Ю. Векслер, в котором публикуется значительное число архивных источников, воссоздаётся культурная атмосфера Вены рубежа XIX$\mathrm{XX}$ веков, эпохи Первой мировой войны, 1920-1930 годов. Впервые освещаются некоторые важные стороны деятельности и взглядов композиторов Нововенской школы. В приложениях помещены уникальные рукописные документы и полный список сочинений композитора. Однако специфика биографического исследования обусловила отсутствие аналитических очерков [1]. Из известных зарубежных источников обращают на себя внимание работы Т. Эртельта [5], К. Льюиса [6], У. ДеФотиса [4] и др. В них кратко характеризуется образный строй Четырёх пьес для кларнета и фортепиано ор. 5, затрагиваются вопросы звуковысотной организации и формы, указываются интересные тембровые находки, специфические приёмы и способы звукоизвлечения.

Цель статьи заключается в осмыслении особенностей камерно-инструментального ансамбля в Четьрёх пьесах для кларнета и фортепиано ор. 5 с точки зрения трактовки технико-выразительных возможностей кларнета и ролевых функций партий.

Изложение основного материала. Четыре пьесы для кларнета $и$ фортепиано ор. 5 А. Берга, созданные в 1913 году, по мнению Томаса Эртельта (Thomas Ertelt), служат образцом «“короткой пьесы” в камерной музыке: самая краткая занимает девять тактов, самая длинная двадцать, но вместе они звучат не дольше восьми минут» [5:1217]. С этой точки зрения, считает автор, они выдержаны в традициях, установленных А. Шёнбергом в Шести маленьких пьесах для фортепиано 
op. 19 (1911) и А. Веберном в ор. 5-11. Учитывая характер энциклопедического издания, для которого была написана статья, Т. Эртельт отмечает некоторую полемичность существующих точек зрения на берговскую музыку. Автор, ссылаясь на Т. Адорно, пишет о попытках усмотреть в Четырёх пьесах ор. 5 черты сонатного цикла. Не отвергая окончательно такую позицию, музыковед не находит её достаточно убедительной. В качестве аргументов он приводит указание самого композитора разделять пьесы продолжительными паузами и особый склад этой музыки, статическая энергетика которой мало способствует мотивному развитию при наличии интонационных связей. Тем не менее, Т. Эртельт пишет: «Сонатные моменты сильнее всего заметны в первой пьесе, в разработке тем, которую венчает страстный танцевальный жест (Tanz-Geste - В. М.); явно обозначенная реприза сразу же стихает в красочной игре многозвучного квартаккорда на ррpp. Повторяющаяся мажорная терция второй пьесы (Sehr langsam) непосредственно отсылает к терциям из ор. 19 Шёнберга² ${ }^{2}$ Своим звучанием выделяется кларнет, исполняющий одинокую кантилену. Сильным контрастом здесь (как и далее) воспринимается третья пьеса, которая благодаря трёхчастности и характеру производит впечатление малого скерцо. Четвёртая, последняя, пьеса предстаёт после этого большой, эффектной сценой» [5:1217].

Для осмысления степени изученности Четырёх пьес для кларнета u фортепиано ор. 5 А. Берга обратимся к научной литературе, посвящённой данному сочинению. Исходя из разнородности представлен-

\footnotetext{
${ }^{1}$ Уточним, что музыковед имеет в виду произведения разных жанров с различным составом исполнителей, подчёркивая тем самым тяготение к миниатюре как отличительную черту композиторов-нововенцев. Приведённые в качестве примера опусы А. Веберна включают: Пять пьес для струнного квартета ор. 5 (1909), Шесть пьес для большого оркестра ор. 6 (1909), Четыре пьесы для скрипки и фортепиано ор. 7 (1910), Две песни для голоса и ансамбля на сл. Р. М. Рильке ор. 8 (1910), Шесть багателей для струнного квартета ор. 9 (1911, 1913), Пять пьес для оркестра ор. 10 (1911, 1913), Три маленькие пьесы для виолончели и фортепиано ор. 11 (1914).

${ }^{2}$ Очевидно, речь идет о второй пьесе шёнберговского фортепианного цикла, которая, по замечанию Н. Власовой, «вся <..> основана на повторяющейся терции $g^{l}-h^{l}<\ldots>$. Терция - господствующий интервал этой миниатюры $<\ldots>$ » [2:229].
} 
Особенности интерпретации инструментальных партий в «Четырёх пьесах...

ных в работах исследовательских задач, условно можно выделить несколько тенденций.

Первая тенденция связана с решением сугубо теоретической проблематики. В качестве примера приведём статью Кристофера Льюиса (Christopher Lewis) «Тональный центр в атональной музыке» (Tonal focus in atonal music) [6]. В ней автор предлагает развёрнутое рассмотрение звуковых структур, выявляющих частое использование трезвучных элементов, сходство между заключительными сегментами в движении кларнета I и III, II и IV частей, композиционную роль $D$ как центрального тона системы.

Вторая тенденция сочетает анализ музыкального текста с исполнительскими задачами. В частности, Уильям ДеФотис (William DeFotis) констатирует, что композитор использовал при создании данного сочинения два противоположных подхода: во-первых, «опуская ожидаемые продолжения и разрешения», он тем самым создавал «неоконченное начало», во-вторых, «интерполируя преобразования материала», останавливался на ключевых моментах этих преобразований [4:131]. Данная ситуация порождает множество исполнительских проблем, в том числе ансамблевого свойства. Об этом свидетельствуют аналитические наблюдения автора. «Возможно, - пишет исследователь, - Берг решил сочинить контрапунктическим методом: кларнет играет одну фразу, которая постепенно движется к излагаемой у фортепиано гармонии; и наоборот, фортепиано направлено к мелодическому утверждению» [4:134]. Не менее важно для достижения полноценного художественного результата требование внимательного отношения к тому, что композитор объединяет посредством лиги последний звук мелодической структуры с последующей паузой. Музыковед объясняет берговский приём на примере первого такта опуса, подчёркивая, что знак «молчания» необходимо воспринимать в непосредственной связи с предшествующим, а не как кратковременный перерыв в процессе континуального мелодического развёртывания. Благодаря этому рождается ощущение недосказанности, поиска постоянно ускользающей мысли, «лирического вздоха». Избранные автором установки определяют привлечение им различных слагаемых музыкального языка и средств выразительности для облегчения процесса разучивания нотного текста участниками ансамбля и осмысления композиторских 
указаний в качестве информационных единиц художественного замысла.

К этой же тенденции можно отнести и работу Дитера де ла Мотта (Diether de la Motte), хотя учёный затрагивает исполнительские проблемы косвенно. Начиная рассуждения с констатации непривычного соотношения «щедрых пауз» после каждой пьесы и звучащей музыки, поскольку «сами пьесы чрезвычайно короткие - в 12, 9, 18 и 20 тактов», автор сразу же переходит к анализу темповых указаний, очевидно, вследствие того, что при малых масштабах пьесы содержат большое количество их изменений [7:131]. «Так, - пишет музыковед, - в двенадцати тактах первой пьесы мы находим тринадцать указаний темпа. Во второй пьесе $<\ldots>$ восемь $<\ldots>$ в девяти тактах, которые, однако, лишь в незначительной мере меняют скорость: очень медленно, медля, медленнее, дайте время, ritenuto, a tетро, ritenuto, ещуе медленнее. Третья пьеса, напротив, содержит меньшее число темповых изменений, но зато более значимое, делящее пьесу на три ярко контрастирующие части - очень быстро - медленные четверти - очень быстро. Похожая ситуация и с четвёртой пьесой, которая идет от медленно через ещзе медленнее до более подвижного темпа и оканчивается снова очень медленно» [7:132]. Детально останавливаясь на первой пьесе, вычерчивая график её темповых изменений, Д. де ла Мотт приходит к интересному заключению, что при отсутствии основного темпа она содержит «событие основного темпа», которое формулируется им как «медленнее, чем...». Причём данная тенденция характерна, по его мнению, для всего цикла.

В чём же состоит пафос аналитических наблюдений музыковеда? Почему во главу угла им избран темповый профиль берговского опуса? Выявленная исследователем «ниспадающая тенденция» обнаруживает себя и в мелодическом движении первой пьесы, будь то регистровое расположение партий или интервальных ходов. Целью столь скрупулёзного разбора становится выяснение интонационных связей в необычной по звуковысотной организации музыке. «Во всеобщем родстве, - заключает автор, - понятие родства, однако, теряет свой смысл, потому что нельзя будет установить вообще ничего неродственного» [7:137]. Этот тезис служит основанием для отказа в правомочности использования понятия мотива. Аналогичная ситуация прослеживает- 
Особенности интерпретациии инструментальных партий в «Четырёх пьесах...

ся музыковедом и в области ритма, поскольку в фортепианной партии обе руки «стремятся к полной самостоятельности и постоянному новаторству», а в отношении кларнета и фортепиано нельзя говорить о ритмических совпадениях [7:137-138]. Проведённый анализ позволяет автору прийти к выводу о том, что при самоограничениях, связанных с избеганием трезвучий и резких диссонансных сочетаний, А. Берг руководствуется конкретной художественной задачей. В силу этого в кульминационный момент пьесы он прибегает к приёму секундовых напластований, напротив, в конце для достижения эффекта угасания оперирует кварто-тритоновыми сопряжениями. Ещё один из интересующих исследователя аспектов касается соотношения кларнета и фортепиано в звуковом пространстве, что позволяет обнаружить полифоническое взаимодействие в пьесе трёх «голосов», которые «делают похожее, но никогда не одно и то же, в разное время» [7:143]. И далее музыковед поясняет: « <...> нет ни ведущего голоса, ни сопровождающего. Отсюда вытекает, что имеется в виду не ясная ритмикомелодическая деталь, а её оспаривание, постоянное наслаивание трёх различных процессов, <..> трёхголосный состав» [там же]. Таким образом, Д. де ла Мотт не касается ни образного строя пьес, ни логики драматургического развития внутри опуса, ни особенностей кларнетовой партии, поскольку сочинение А. Берга требовало поиска новых аналитических подходов для осмысления способов конструирования музыки вне привычных тональных закономерностей - вопрос, имеющий принципиальное значение для всей новейшей музыки XX века.

Tретья тенденция отличается взаимодействием аналитического подхода с выявлением образно-семантического значения функционирующих в музыкальном тексте берговской музыки элементов. Так, на факт выбора пьес ор. 5 для формальных исследований указывает Петер В. Шатт (Peter W. Schatt), видя при этом свою задачу в восполнении пробелов, связанных с изучением числовых структур, их символической и криптограмматической ${ }^{1}$ функций [8:284]. Отталкиваясь от выводов Д. де ла Мотта, исследователь останавливается на последних тактах первой пьесы, подчёркивая их итоговое значение: «<..>

\footnotetext{
${ }^{1}$ Напомним, что криптограмма - с греческого «тайнопись» - предполагает знание или нахождение ключа для расшифровки сообщения.
} 
тут полностью отсутствует мелодика как движение звуковых высот, а ритм подчиняется идее не только выписанного, но и предписанного ритардандо. Вместе с диминуэндо от $p$ до рррр эти явления производят впечатление, как будто композитор $<\ldots>$ тонет в потоке времени, недолговечности которого он как раз попытался противопоставить фрагмент абсолютно оформленного воспоминания. Таким образом, эти три последних такта не только олицетворяют воплощение структуры пьесы, но и < ..> документируют глубочайший лирический общий тон, из которого она вырастает» [8:129]. Рассматривая далее процесс завоевания звукового пространства, с одной стороны, и повторность звуковых структур, с другой, - музыковед выводит определённые закономерности, в основе которых лежит число 5, результат его умножения на два (как это, замечает автор, будет позже встречаться в Камерном концерте и Лирической сюите) и 7, предлагая разные возможные интерпретации происхождения последнего. Высказанные П. Шаттом соображения семантического и формального свойства с учётом удержанного характера большой терции становятся связующей нитью при анализе последующих пьес, что служит дополнительной аргументацией в пользу их тесной взаимосвязи.

Невольно напрашивается параллель с ключевыми понятиями художественно-эстетических постулатов А. Веберна, согласно которым взаимосвязь посредством повторности обеспечивает постижимость музыкальной мысли. Определяя проблематику его лекций о музыке, они отразили ситуацию, характерную не только для творчества представителей нововенской школы, но и всех авангардно ориентированных композиторов современности. Вопросы взаимоотношения многообразия и единства, по мнению В. и Ю. Холоповых, «есть древнейшая проблема теории искусства. Если для прежней музыки факторы единства были заранее заданными в виде обязательных для всех общих правил искусства, то для новой музыки XX века они отпали, и композитор оказался перед лицом опасности хаоса вследствие катастрофической недостаточности фактора единства, закономерности, порядка. Отсюда напряжённые поиски новых форм скрепления <..>» [3:141-142]. Отсюда же, добавим, направленность теоретической мысли при рассмотрении многих образцов новейшей музыки, в том числе Четырёх пьес для кларнета и фортепиано ор. 5 А. Берга. 
Особенности интерпретациии инструментальных партий в «Четырёх пьесах...

Возвращаясь к статье П. Шатта, укажем на предпринятую автором интерпретацию структурно-высотных закономерностей берговских пьес. Музыковед пишет: «Касательно объяснения того факта, что именно $h, b$ и $a$ играют экспонирующую роль, и что формообразующую функцию выполняют 5 и особенно его двукратное - 10 (а не другие, возможно более символичные числа), есть ссылка, принадлежащая перу Берга; она допускает возможность того, что также и в основе пьес для кларнета лежит эзотерическая программа» [8:132]. Рассуждая далее, немецкий исследователь утверждает, что звуки $a$ и $b$, играющие заметную роль в первой пьесе, можно понимать как криптоним имени и фамилии композитора, а тон $g$ в её конце в качестве заключительной буквы его фамилии. Последний тезис П. Шатт аргументирует следующими соображениями: «<..> во-первых, композитор наделяет его особым весом благодаря частым повторам, во-вторых, один нюанс нотного письма в 7-м такте указывает на то, что Берг со своим $g$ - также как и с $a$ и $b$ - преследовал на композиционном уровне не только чисто музыкальные, то есть слышимые уже на уровне слухового восприятия, интенции; удвоение в правой руке у фортепиано $b$ и $g$ с помощью второго голоса $<\ldots>$ можно считать письменным знаком того, что Берг придавал этим тонам дополнительное, выходящее за пределы музыкального контекста, значение» [8:133]. В таком ключе, считает учёный, следует рассматривать и звук $h$ - «заключительную точку» первой пьесы, его связь с тонами $a$ и $b$ в четвёртой миниатюре, а именно, как шифр имени Helene - жены композитора. Этими фактами П. Шатт поясняет любовь А. Берга к специфическим числовым пропорциям: «10 букв содержит имя Helene Berg, а сумма букв полных имени и фамилии её супруга (Albano Berg) также равняется 10» [там же]. Однако, продолжает автор, это не разъясняет при таком способе природы числа 5. Оно, по мысли музыковеда, могло возникнуть лишь как результат обращения в тона букв имён и фамилий обоих супругов: $a b g$ и $h e$. Вывод, который следует за этими рассуждениями автора, представляет интерес для интерпретаторов этой музыки, поскольку касается непосредственно её содержательной стороны: «Если таким образом понимать звуковую констелляцию финала первой пьесы криптографически и числово-символически, то её можно трактовать как знак встречи Хелене и Альбана Берга; и тогда станут понятными основания, с од- 
ной стороны, для её функционирования, по сути, в качестве того, что делала до этого прикладная техника композиции, с другой стороны, для выражения лирической углублённости и истаивания: в лирической погружённости в себя композитор прислушивается к тому, как звуковые структуры в качестве носителей музыкального и содержательного смысла в силу столкновения с отошедшими в прошлое драматизмом и чувствительными мгновениями ещё раз увековечивают воспоминания» [8:134]. Отталкиваясь от выявленных закономерностей, П. Шатт даёт свое понимание образного строя Четьрёх пьес для кларнета $u$ фортепиано ор. 5: первая пьеса соединяет «в порой неистовых порывах элементы поиска и обретения», вторая - демонстрирует покой как результат их общности, при этом повторность большой терции $(d-f i s$ в партии левой руки - В. М.), сопровождающей широкую кантилену у кларнета, расшифровывается на основе числовой символики, напряжение же, возникающее благодаря балансированию между благозвучием и диссонансом, а позднее из-за расхождения артикуляции и динамики, может «справедливо считаться зеркалом биографических обстоятельств»; третья пьеса предстаёт «капризным интермеццо» между мечтательной второй и насыщенной звуковой символикой четвёртой [8:134]. Завершающая опус, она отмечена выразительно сдержанным развитием от состояния чрезвычайного покоя до бьющего через край драматизма. Ещё раз, указывая на обыгрывание в ней всех ключевых с точки зрения криптографии тонов, музыковед высказывает мысль о том, что определённую часть творчества А. Берга можно понимать «как переложение на музыку некоторых аспектов его биографии». И добавляет: «Для пьес для кларнета такой способ сочинения музыки можно считать легитимным - это не было эпигонским программным сочинительством 19 века, и учитывая временную сторону пьес, они не были “рассказами”, а лирическими вспышками сложных обстоятельств. <..> финал отсылает в ту область музыкального выражения, где слова утрачивают силу» [8:135].

Какие же трудности технического и выразительного плана возникают перед кларнетистом при исполнении пьес ор. 5 А. Берга? Как свидетельствует представленная литература, исполнитель, прежде всего, должен познакомиться с научными изысканиями, чтобы облегчить последующий интерпретационный процесс. Это важно для понимания 
Особенности интерпретациии инструментальных партий в «Четырёх пьесах...

не только образно-эмоциональной и содержательной стороны музыки, но и новизны ансамблевого соотношения инструментальных голосов. С этой точки зрения кларнетист должен осознавать свою партию и в её индивидуальных особенностях, и как составную часть единого тематического процесса. Целесообразно напомнить, что предшествующая музыкальная практика сформировала разные типы соотношения партий в инструментальном дуэте, среди которых назовём: «рельеф - фон», когда одноголосный инструмент несёт основную мелодическую нагрузку, а фортепиано выполняет функцию сопровождения; «диалог», подразумевающий взаимообмен тематическим материалом и перемену ролевых функций; «контрапункт» разнотембровых голосов, каждый из которых наделён индивидуальными свойствами (данный тип нередко задействуется эпизодически как средство выявления сложного психологического состояния и обострения интонационных событий). Атонализм Четырёх nьес оp. 5 , связанный с избеганием тональных ориентиров и опорой на выразительность интервальных сцеплений, предопределил возникновение нового качества ансамблевой техники, заявляющего о себе в нивелировании понятия солирующего тембра, приёмов аккомпанирования, открытого взаимообмена тематическим материалом. Внешне все названные приметы присутствуют в нотном тексте, однако сама техника письма направляет музыкальный процесс в сторону создания единого интонационного пространства, в котором участвующие темброво-регистровые «индивидуальности» предстают слагаемыми многоголосной фактуры. Несмотря на это, идея ансамблевости в широком смысле сохраняется, что и позволяет рассмотреть кларнетовую партию в качестве относительно самостоятельного явления.

Итак, собранные в опус пьесы предполагают владение разнообразной палитрой артикуляционно-динамических средств, способных передать тонкую смену лирических настроений. Их контраст экспонируется уже в первой пьесе, что нацеливает исполнителя на быстрое переключение в иной эмоциональный настрой в условиях отсутствия масштабных тематических структур. Наибольшим мелодическим наполнением отмечена первая половина пьесы, причём А. Берг задействует приём волнового развития музыкальной мысли, начиная с $a s^{2}$. Заметим, что выставленный композитором знак $p$ при отсутствии фор- 
тепианной поддержки создаёт определённые трудности, связанные с необходимостью избегания излишней атаки при достижении полноценного звучания. Плавность звуковедения при наличии широких ходов и смене штрихов, микродинамика, выделение отдельных оборотов, на что указывают многочисленные авторские ремарки (легко, тяжелее, выразительно, аккомпанируя), темповые сдвиги (умеренно, постепенно замедляя, медленно, замедляя, очень медленно, замедляя, постепенно ускоряя, в темпе и т. п.) свидетельствуют об ориентации композитора на быструю исполнительскую реакцию и безупречную ансамблевую согласованность. Уместно в связи с этим отметить ремарку, выставленную для верхнего голоса фортепианной партии - «всё время выдвигаясь». Уже в шестом такте достигается яркая кульминация: в партии кларнета выставляется длительная трель, quasi Flatterzunge, динамика достигает $f f f$; партия фортепиано записана здесь на трёх нотных станах, и все интонационные структуры дифференцированы не только фактурно, но и с помощью дополнительных выразительных приёмов. Так, аккордовые гроздья в партии правой руки арпеджированы, взяты под одну лигу, снабжены ремаркой «полнозвучно» (voll), «дать время»(Zeitlassen); средний голос, порученный левой руке в качестве мелодического рельефа, выделен акцентами и указанием marcato; наконец, бас представлен арпеджированным нисходящим движением больших и малых септим. Достигнутая кульминация знаменует собой прорыв драматизма, образуя обширную зону (вместе со спадом она занимает 4 такта из 12 всей пьесы). Оформление композитором постепенного снятия напряжения подтверждает наблюдения исследователей о родстве и одновременно не-родстве инструментальных голосов. В данном случае имеются в виду не только сам музыкальный материал, но и комплекс технико-выразительных приёмов. В частности, fff секундовых созвучий в партии левой руки с синкопами и ритмической прогрессией, сопровождающие мелодический рельеф с нерегулярной акцентикой отдельных тонов и требованием постепенного diminuendo, сочетаются с выразительными репликами кларнета, одна из которых, начинаясь на $f$ и постепенно ускоряясь, должна словно улетучиться (flüchtig); следующий за ней развёрнутый оборот содержит требования ritenuto, короткой ферматы, $m f$, espressivo, а затем ohne Ausdruck («без выразительности»). Напротив, в фортепианной партии 
Особенности интерпретации инструментальных партий в «Четырёх пьесах...

правой руки А. Берг выставляет molto espressivo, а в левой - flüchtig. Как видим, несмотря на то, что кларнетовая, как и фортепианная, партия достаточно трудна в ритмическом, интонационном отношении, основную сложность представляют именно выразительные средства и осмысленное совместное музицирование.

На фоне многособытийной первой пьесы две серединные отличаются выдержанностью образного плана. Отсюда более скромная палитра штрихов, артикуляционных, темповых, динамических изменений. Подобного рода композиторская установка во многом обусловлена тем, что они укрупняют смысловые идеи, которые были намечены в начале опуса. Благодаря этому возникает яркий контраст, резкая перемена эмоционального состояния. Достаточно указать, что вторая пьеса идёт в очень медленном темпе (sehr langsam), в то время как третья - очень быстро (sehr rasch); господству legato противопоставлена обострённость staccato (что не исключает задействования legato в качестве фразировочного приёма); фактуре «рельеф-фон» - «диалог» и полифоническое изложение. Вместе с тем А. Берг не отказывается от режиссирования исполнительского процесса. Обе пьесы снабжены детальными рекомендациями типа «медлительно» (zögernd), «дать время» (Zeitlassen), «в темпе не торопясь» (a tempo nicht eilen), «ещё медленнее» (noch langsamer) - во второй пьесе; «немного медленнее, но все же очень быстро» (etwas langsamer, aber immer sehr rasch), «очень торопливо» (sehr hastig), «так быстро и легко, как можно» (so rasch und leise als möglich) - в третьей пьесе. Несмотря на скерцозный характер, третья пьеса, так же как и предшествующая, выдержана в тихой звучности. Более того, если в лирической миниатюре встречаются $m f$ и даже $f$ (однако «относительное» - relatives Forte), появляющиеся как средство выделения некоторых звуков, то «интермеццо» (П. Шатт) отличается тишайшей динамикой, в которой $p$ является самой громкой звучностью. Среди динамических эффектов отметим приём «эхо» в обеих пьесах, среди артикуляционных - marcato во второй и Flatterzunge в третьей. Детализация подобного рода повышает требования к качеству исполнения и выявляет подлинно виртуозный характер миниатюр при отсутствии традиционных концертных признаков.

Финал ор. 5 сродни первой пьесе наличием контрастных элементов. О его сложности свидетельствуют: насыщенная фактура форте- 
пианной партии, отличающейся сложным ритмическим рисунком; разнородность приёмов в партии кларнета, где выразительная сольная кантилена соседствует с фоновым тремоло, угловатыми мотивами non legato, выписанными группетто тридцатьвторых в соотношении 9:1; регистровый разброс; резкие динамические градации от $p$ до $f f$. Композитор и здесь остаётся верным себе, прописывая все темповые, динамические, выразительные средства. Напомним, что требование длительных пауз между пьесами, с одной стороны, помогает переключению в иное эмоциональное состояние, с другой стороны, усложняет акт исполнения в силу того, что ансамблисты должны найти ту меру выдержанности тишины, которая, удерживая впечатления от предшествующего, не разрушает непосредственного контакта со слушательской аудиторией. Нельзя обойти вниманием тот факт, что при отсутствии экстраординарных новаций в сфере исполнительства композитор открывает путь дальнейшим новоисканиям. В частности, показательны заключительные 4 такта финала: на фоне «неслышно придавленного» (unhörbar niederdrücken) большого септаккорда на звуке $c$, поддержанного педалью и секундовыми созвучиями в низком регистре на $f f f$, sfffz, которые вызывают к жизни обертоновый шлейф, печальным голосом звучит кларнет, истаивая в тишине.

Выводы и перспективы. Обобщая аналитические наблюдения, в том числе в известной нам литературе, и оценивая творческие открытия А. Берга в Четырёх пьесах для кларнета и фортепиано ор. 5 с учётом последующей композиторской практики, выделим несколько принципиальных, на наш взгляд, моментов. Этот опус, во-первых, отличается радикальным обновлением музыкального языка, прогнозируя раздвижение границ устоявшейся традиции; во-вторых, стал родоначальником нового типа ансамбля; в-третьих, позволил трактовать паузу как важную составляющую часть художественного замысла, как образ осмысленной тишины; в-четвёртых, продемонстрировал новое понимание программности, основанной на символике звуков и чисел; в-пятых, выявил глубинную связь с традицией при изменении музыкальных закономерностей. В таком контексте от Четырёх пьес для кларнета и фортепиано ор. 5 А. Берга протягивается множество нитей к сочинениям композиторов, принадлежащих различным поко- 
Особенности интерпретации инструментальных партий в «Четырёх пьесах...

лениям и национальным культурам, очерчивая широкое поле перспективных научных изысканий. Сказанное позволяет говорить о весомом значении этого опуса в истории развития кларнетовой - не только ансамблевой, но и сольной, музыки.

\section{ЛИТЕРАТУРА}

1. Векслер Ю. С. Альбан Берг и его время. Опыт документальной биографии. Санкт-Петербург : Композитор, 2009. 1136 с.

2. Власова Н. О. Творчество Арнольда Шёнберга. Москва : URSS, 2010. 527 с.

3. Холопова В. Н., Холопов Ю. Н. Антон Веберн. Жизнь и творчество. Москва : Сов. композитор, 1984. 320 с.

4. DeFotis W. Berg's Op. 5: Rehearsal Instruction. Perspectives of New Music. 1978. Vol. 17. № 1. P. 131-137.

5. Ertelt T. Berg, Alban (Albano Maria Joannes). Die Musik in Geschichte und Gegenwart : 26 Bd. in 2 T. / berg. von Friedrich Blume. - 2., neubearb. Ausg. / hrsg. von Ludwig Finscher. Kassel [etc.] : Bärenreiter, 1999. Personenteil 2. Sp. 1198-1238.

6. Lewis Chr. Tonal Focus in Atonal Music: Berg's op. 5/3. Theory Spectrum. 1981. Vol. 3. P. 81-97.

7. Motte D. Alban Berg: Vier Stücke für Klarinette und Klavier op. 5, № 1. Musikalische Analyse. Textteil / Diether de la Motte. 8. Aufl. Kassel [etc.] : Bärenreiter, 2007. S. 131-145.

8. Schatt P. W. Zahl, Symbolik und Kryptogrammatik in Alban Bergs Stücken für Klarinette und Klavier. Archiv für Musik-Wissenschaft / hrsg. Hans Heinrich Eggebrecht. Stuttgart : Franz Steiner, 1986. Jg. XLIII, H. 2. S. 128-136.

\section{REFERENCES}

1. Veksler, Y. (2009). Alban Berg i ego vremya. Opyit dokumentalnoy biografii [Alban Berg and his time. Experience documentary biography]. St. Petersburg: Kompozitor, 1136 p. [in Russian].

2. Vlasova, N. (2010). Tvorchestvo Arnolda ShYonberga [Creativity of Arnold Schönberg]. Moscow: URSS, 527 p. [in Russian].

3. Kholopova, V. and Kholopov, Y. (1984). Anton Vebern. Zhizn i tvorchestvo [Anton Webern. Life and Art]. Moscow: Sovetskiy kompozitor, 320 p. [in Russian].

4. DeFotis, W. (1978). Berg's Op. 5: Rehearsal Instruction. Perspectives of New Music, 17 (1), pp. 131-137. [in English]. 
5. Ertelt, T. (1999). Berg, Alban (Albano Maria Joannes). In: Die Musik in Geschichte und Gegenwart, 2nd ed. Kassel [etc.]: Bärenreiter, SS. 1198-1238. [in German].

6. Lewis, C. (1981). Tonal Focus in Atonal Music: Berg's op. 5/3. Theory Spectrum, 3, pp. 81-97. [in English].

7. Motte, D. (2007). Alban Berg: Vier Stücke für Klarinette und Klavier op. 5, № 1. In: D. Motte, ed., Musikalische Analyse. Textteil, 8th ed. Kassel [etc.]: Bärenreiter, SS. 131-145. [in German].

8. Schatt, P. (1986). Zahl, Symbolik und Kryptogrammatik in Alban Bergs Stükken für Klarinette und Klavier. Archiv für Musik-Wissenschaft, 43 (2), SS. 128 136. [in German].

Стаття надійшла до редакиї̈ 09.01.2019 р.

УДК 791.636:781.65](045)

ORCID 0000-0001-6694-8329

\section{Юлія Коваленко}

Харківська державна академія культури

КОМПОЗИЦІЯ ТА ІМПРОВІЗАЦІЯ

В АСПЕКТІ ВПЛИВУ МУЗИКИ

НА ВИРАЖАЛЬНУ СТРУКТУРУ ФІЛЬМУ

Коваленко Ю. Б. Композиція та імпровізація в аспекті впливу музики на виражальну структуру фільму. Виявлено особливості взаємодії музики з кіномистецтвом, зокрема, вплив музичного мислення, як поєднання композиційного та імпровізаційного процесів, на виражальну систему фільму та специфіку кінотворчості. Прослідковано властиві музиці композиційні закономірності, стабільні та мобільні елементи музичного формотворення у сюжетній структурі, драматургічному розвитку, образно-змістовому та виразному комплексі кінотвору. На прикладі фільмів за участю джазу, зокрема біографічного, нуару, «джазового» кіно, а також більш масштабного жанру кінодрами із залученням музики різних стилів, проаналізовано роль музичного супроводу у сюжетній та позасюжетній оповіді, відбиття суто музичних форм та жанрів, принципів музичного розвитку та особливостей мислення у пластиці зображальної виразності, архітектоніці та драматургії екранного твору. 3'ясовано, завдяки чому музика як абстрактно-чуттєвий вид мистецтва сприяє емансипації кіномови по відношенню до вербальної складової на користь поетичного способу висловлення. 